\title{
Erythema multiforme associated with herpes labialis
}

\section{Jacinto Orgaz-Molina MD, Salvador Arias-Santiago MD PhD}

\section{Competing interests: None} declared.

This article has been peer reviewed.

Affiliation: Department of Dermatology, San Cecilio University Hospital,

Granada, Spain

\section{Correspondence to:} jacinto_orgaz@hotmail.com

CMAJ 2013. DOI: 10.1503 /cmaj.121307

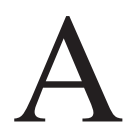
35-year-old woman presented to the emergency department with a recurrent rash on the backs of both hands related to what she described as a "fever blister" on her lower lip. In the previous 2 years, she had experienced more than 12 similar eruptions involving both her lip and hands. She was not taking any medications. On examination, the centre of the vesicle on the patient's lip was yellowish, and the backs of both hands showed red papules and some red plaques with necrotic centres, consistent with target lesions (Figure 1). We diagnosed erythema multiforme secondary to recurrent herpes labialis.

Erythema multiforme is a self-limited hypersensitivity reaction involving both skin and mucous membranes. The most common condition

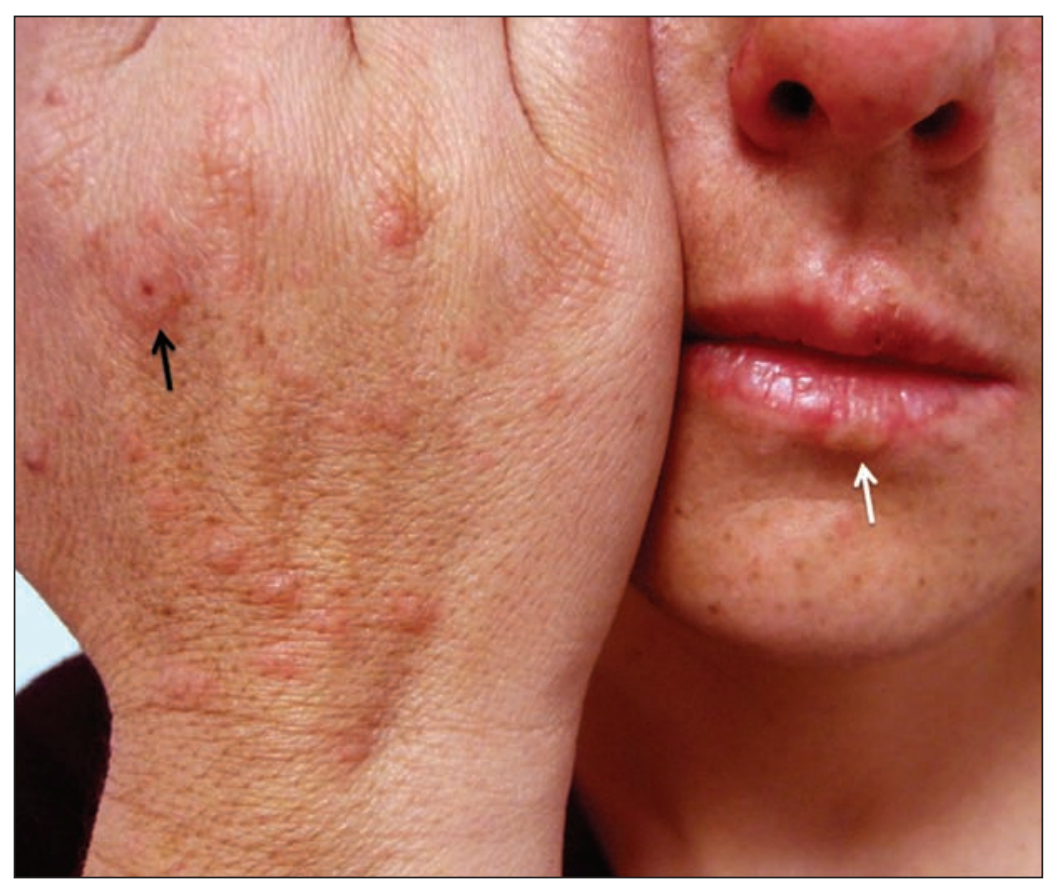

Figure 1: A vesicle with yellowish content on the lower lip of a 35-year-old woman, compatible with herpes labialis (white arrow). Multiple erythematous and edematous papules and plaques, one with central necrosis (black arrow), can be seen on the back of the patient's hand, consistent with erythema multiforme. associated with recurrent erythema multiforme is herpes simplex virus, but a cause cannot be identified in most cases (about 60\%). ${ }^{1}$ Other known associations with recurrent erythema multiforme include complex aphthosis, bacterial infection (e.g., Mycoplasma pneumonia), adverse drug reactions and menstruation. ${ }^{1,2}$

The lesions of recurrent erythema multiforme typically resolve in 1-2 weeks and are selflimited. When associated with herpes simplex virus, the duration of episodes can vary in the same patient and are directly related to intralesional expression of viral genes. ${ }^{3}$ When there is mucosal involvement by herpes simplex virus or erythema multiforme, severe symptoms or a high rate of recurrence (as in our patient's case), treatment and prophylaxis with antiviral agents may be considered. ${ }^{4}$ Oral acyclovir has shown to be effective for prophylaxis, with valacyclovir and famciclovir providing alternate options. ${ }^{4}$ Antiviral prophylaxis is often effective at preventing erythema multiforme associated with herpes simplex virus. Although other systemic therapies such as azathioprine, dapsone or immunoglobulins have been described, limited evidence supports their efficacy in the treatment of acute episodes. ${ }^{2}$ An effective vaccine against herpes simplex virus may eventually prove to be the most desirable intervention. ${ }^{5}$

\section{References}

1. Wetter DA, Davis MD. Recurrent erythema multiforme: clinical characteristics, etiologic associations, and treatment in a series of 48 patients at Mayo Clinic, 2000 to 2007. J Am Acad Dermatol 2010;62:45-53.

2. Sokumbi O, Wetter DA. Clinical features, diagnosis, and treatment of erythema multiforme: a review for the practicing dermatologist. Int J Dermatol 2012;51:889-902.

3. Kokuba H, Imafuku S, Burnett JW, et al. Longitudinal study of a patient with herpes-simplex-virus-associated erythema multiforme: viral gene expression and T cell repertoire usage. Dermatology 1999;198:233-42.

4. Woo SB, Challacombe SJ. Management of recurrent oral herpes simplex infections. Oral Surg Oral Med Oral Pathol Oral Radiol Endod 2007; 103 (Suppl 12): e1-18.

5. Möhrenschlager M, Ring J. Viral vaccines for dermatological disease: some additional information regarding HPV and HSV. J Am Acad Dermatol 2008;59:1090-1. 